Conservation Biology of Freshwater Turtles and Tortoises:

A Compilation Project of the IUCN/SSC Tortoise and Freshwater Turtle Specialist Group

A.G.J. Rhodin, P.C.H. Pritchard, P.P. van Dijk, R.A. Saumure, K.A. Buhlmann, and J.B. Iverson, Eds

Chelonian Research Monographs (ISSN 1088-7105) No.5, doi:10.3854/crm.5.021.atra.v1.2008

(C) 2008 by Chelonian Research Foundation • Published 9 August 2008

\title{
Apalone spinifera atra (Webb and Legler 1960) - Black Spiny Softshell Turtle, Cuatrociénegas Softshell, Tortuga Concha Blanda, Tortuga Negra de Cuatrociénegas
}

\author{
Adrián Cerdá-Ardura ${ }^{1}$, Francisco Soberón-Mobarak ${ }^{2}$, \\ Suzanne E. McGaugh ${ }^{3}$, and Richard C. Vogt ${ }^{4}$
}

\author{
${ }^{1}$ Romero 93 Col.Niños Heroes, C.P. 03440, Mexico D.F. Mexico [mayaquen@cablevision.net.mx]; \\ ${ }^{2}$ Xavier Sorondo 210 Col.Iztaccihuatl, C.P. 03520, Mexico D.F. Mexico [francisco.soberon@sabio.com.mx]; \\ ${ }^{3}$ Department of Ecology, Evolution, and Organismal Biology, \\ Iowa State University, Ames, Iowa 50011 USA [smcgaugh@iastate.edu]; \\ ${ }^{4}$ CPBA/INPA, Caixa Postal 478, Petropolis, \\ Manaus, Amazonas 69011-970 Brazil [vogt@inpa.gov.br]
}

\begin{abstract}
Summary. - Apalone spinifera atra (Family Trionychidae), endemic to the Cuatrociénegas Basin of Coahuila, Mexico, is an enigmatic and severely threatened softshell turtle. On the basis of morphology, it has been regarded as a full species (Apalone ater), but by phylogenetic molecular analyses it is currently considered a subspecies of $\boldsymbol{A}$. spinifera. The discovery of color morphs correlated to substrate coloration in different localities and the recognition of hybridization between $A$. s. atra and $A$. s. emoryi have led to additional taxonomic uncertainty. In addition, $A$. $s$. atra has a very restricted distribution with an apparently small population size that is also being affected by genetic introgression from $A$. s. emoryi. These factors, combined with recent anthropogenic draining and alteration of its limited freshwater habitats, have placed $A$. s. atra at very high risk for extinction in the near future, if careful conservation actions are not taken immediately. In addition, a lack of information about its ecology has made its relationships and survival prospects more difficult to discern. It is listed as Critically Endangered by the IUCN Red List, included on Appendix I of CITES, listed as Endangered by US ESA, and as a Species of Special Concern by the Mexican Secretaría de Medio Ambiente y Recursos Naturales.

Distribution. - Mexico. Restricted to the Cuatrociénegas Basin, Coahuila.

Synonymy. - Trionyx ater Webb and Legler 1960, Trionyx spinifer ater, Trionyx spiniferus ater, Apalone spinifera ater, Apalone ater, Apalone spiniferus ater, Apalone spinifera atra, Apalone atra.

STATUS. - IUCN 2007 Red List: Critically Endangered (CR A1ace, B1+2c) (assessed 1996, needs updating); CITES: Appendix I; US ESA: Endangered; Mexico: Species of Special Concern.
\end{abstract}

Taxonomy. - Apalone spinifera atra was described as a full species, Trionyx ater, by Webb and Legler (1960), from Tío Cándido (type locality), $16 \mathrm{~km}$ southwest of Cuatrociénegas de Carranza, central Coahuila, México. Webb (1962) continued to follow this designation, as did Winokur (1968), whose field and morphological study also considered T. ater to warrant species designation. However, Morafka (1977) empirically considered $T$. ater to be a subspecies of Trionyx spiniferus, and Smith and Smith (1980) concluded that the taxon should be considered a subspecies of spiniferus because $T$. spiniferus emoryi had apparently invaded the Cuatrociénegas Basin through drainage canals constructed in the late $1800 \mathrm{~s}$ and was hybridizing extensively with $T$. ater.

In this regard, it was postulated that $A$. s. atra and $A$. s. emoryi had lived allopatrically for thousands of years, with atra inhabiting some small, isolated spring-fed ponds, lakes and pools, maintaining very small populations, and emoryi, with a wide distribution in northern Mexico and southwestern United States, living in close proximity to atra, but in different hydrologic systems. It was assumed that this situation changed dramatically about 100 years ago when cattle ranchers began to construct channels to extract water, thereby connecting turtle habitats that were previously isolated. As a consequence, A. s. emoryi was postulated to have dispersed through these channels and to invade habitats previously occupied solely by atra, and to have begun to hybridize.

As a result of this postulated scenario, Smith and Smith (1980) hypothesized that the characteristics of atra were being swamped by emoryi, and concluded that ater was already an extinct subspecies by 1979. However, in 1983, a collecting trip by K. Darnell, G. Grall, and A. Wisnieski produced several pure atra (Ernst and Barbour 1992). Another pure female atra was collected in a trammel net together with an A. s. emoryi in July 1986, confirming the continued existence of atra (Cerdá-Ardura, Soberón-Mobarak, and Vogt, unpubl. data). More recently, extensive collections from all major drainages in the Cuatrociénegas Basin by McGaugh during 2003 and 2004 with subsequent morphologic and genetic analyses defined one morphologically pure population at the type locality of Tío Cándido and several other populations (Antiguos Mineros, El Mojarral Este, Anteojo, 


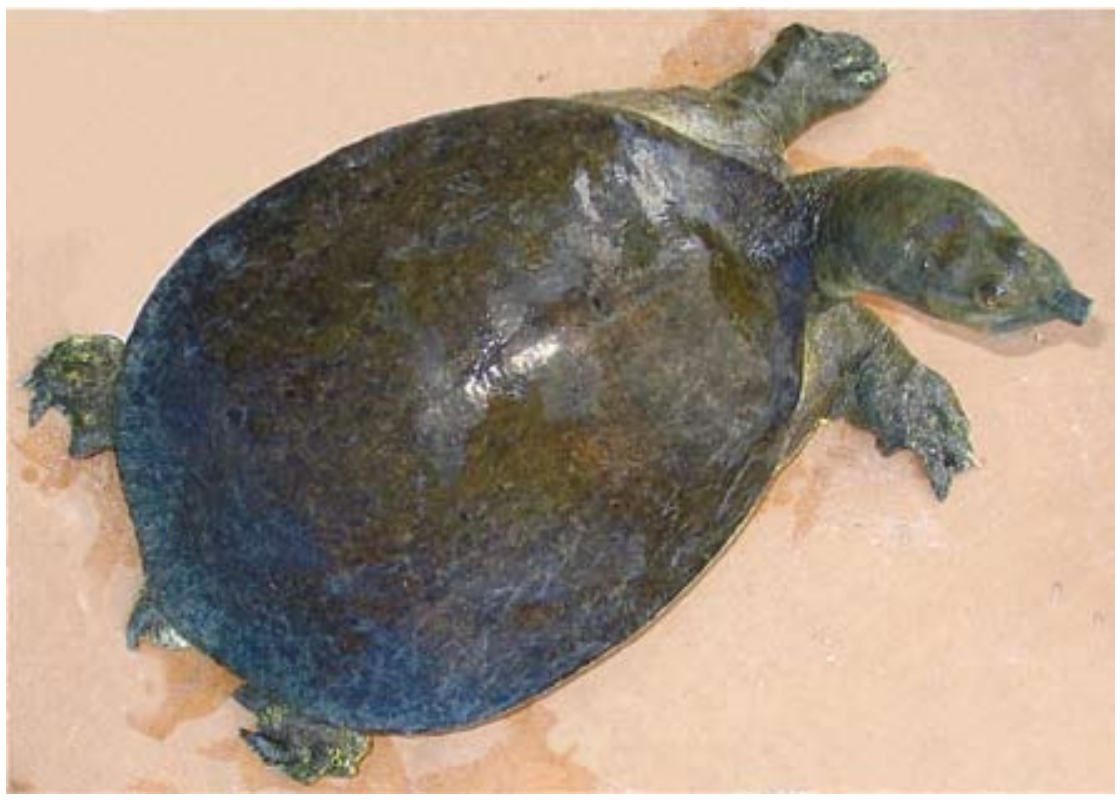

Figure 1. Apalone spinifera atra from Tío Cándido, Cuatrociénegas Basin, Coahuila, Mexico. Photo by Suzanne E. McGaugh.

and Rio Cañon) which contained A. s. emoryi and A. s. atra intermediate morphs.

One mitochondrial marker known to show strong resolving power in Apalone, cytochrome $b$ (Weisrock and Janzen 2000; McGaugh et al. 2008) and three nuclear loci known to show species resolution power in Testudines (Engstrom et al. 2004; Krenz et al. 2004; Le et al. 2006) showed little to no divergence between $A$. s. atra collected from the type locality and A. s. emoryi collected from the Rio Grande (McGaugh and Janzen 2008). As such, McGaugh and Janzen (2008) agreed with the designation by Fritz and Havas (2007) of A. s. atra as a subspecies of A. spinifera. Furthermore, strong correlations exist between substrate colorand dorsal shell coloration of Apalone within the basin (McGaugh 2008), indicating that the dark coloration of A. s. atra may be affected by the environment and possibly be a plastic trait (Bartley 1971).

Description. - The black spiny softshell is a mediumsized aquatic turtle reaching $282 \mathrm{~mm}$ in carapace length. The ovoid carapace is low with fine longitudinal corrugations along the posterior border (often ragged or notched) and

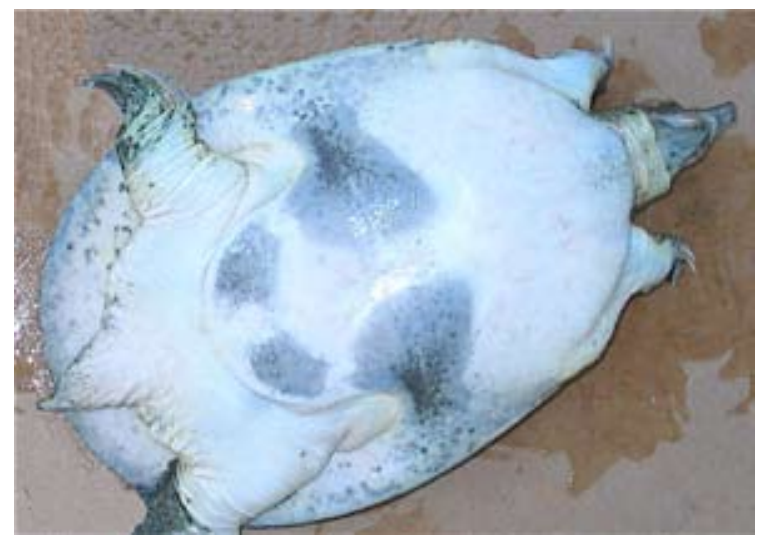

Figure 2. Apalone spinifera atra from Tío Cándido, Cuatrociénegas Basin, Coahuila, Mexico. Photo by Suzanne E. McGaugh. lacks a pale border. Males have reduced septal ridges and are smaller than females. Neither sex has tubercles on the anterior edge of the carapace when adults. Apalone spinifera atra has a uniform, sometimes lichen-like, black, dark gray, or slate colored carapace. The dorsal surfaces of the limbs, neck, and head are uniform in coloration, sometimes with obscure patterns.

Distribution. - Apalone spinifera atra is endemic to permanent warm water ponds in the Cuatrociénegas Basin of Coahuila, Mexico. These ponds are confined to an area near the northernmost extension of the Sierra de San Marcos. This includes the following localities: Poza del Tío Cándido (type locality), El Mojarral Este, Rio Chiquito, Saca del Fuente Canal, Rio Puente Chiquito, La Angostura Canal, Rio Cañon, Anteojo, and Antiguos Mineros Grande (Winokur 1968).

Habitat and Ecology. - Apalone spinifera atra occurs only in permanent, spring-fed and clearwater ponds in the Cuatrociénegas Basin. Morphologically identified specimens are found in deep lagunas and are, to our knowledge, absent from rivers and playa lakes (Winokur 1968; McGaugh and Janzen 2008). Apalone spinifera emoryi is found more often in rivers and playa lakes (Winokur 1968; McGaugh and Janzen 2008) Nothing is known about the ecology, population dynamics, reproduction, or behavior of these two taxa in the Cuatrociénegas Basin,

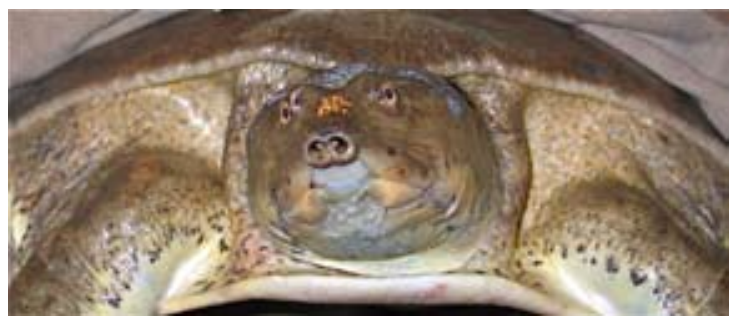

Figure 3. Apalone spinifera atra from Tío Cándido, Cuatrociénegas Basin, Coahuila, Mexico. Photo by Suzanne E. McGaugh. 

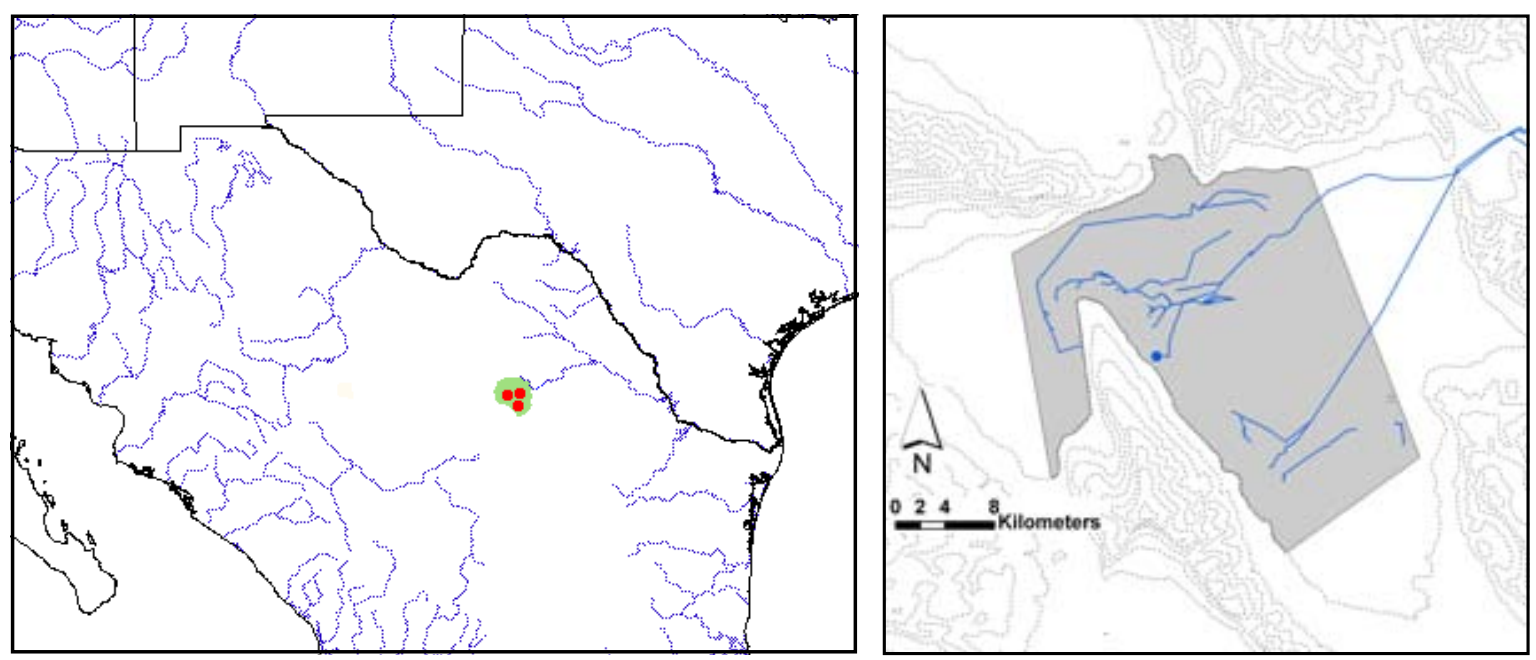

Figure 4. Left: Distribution of Apalone spinifera atra in northeastern Mexico, restricted to the Cuatrociénegas Basin in Coahuila. Red points = museum and literature occurrence records of atra and atra-emoryi intergrades based on published records and authors' data; green shading = projected distribution based on authors' data for atra and atra-emoryi intergrades. Right: Close-up view of Cuatrociénegas Basin showing distribution of atra and atra-emoryi intergrades; the blue dot marks the type locality at Poza del Tío Cándido where the only known pure population of $A$. s. atra occurs.

In terms of potential ecological competition between $A$. s. atra and A. semoryi in the basin, we hypothesize that there may be only partial displacement of atra by emoryi, and that emoryi appears tooccupy different ecological niches from those of atra (Cerdá-Ardura and Soberón-Mobarak, unpubl. data).

PopulationStatus. - WebbandLegler(1960)described the species from nine specimens and pointed out that it was relatively abundant at Tío Cándido. They also mentioned the possibility of

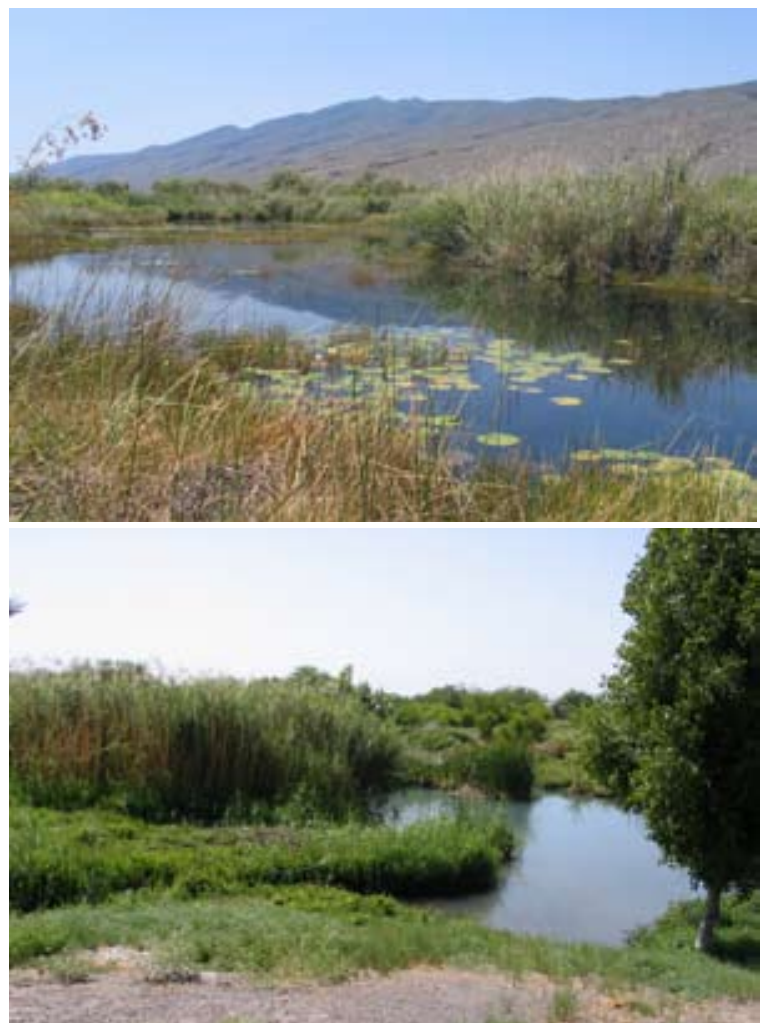

Figure 5. Habitat of Apalone spinifera atra in Cuatrociénegas Basin. Top: Poza del Tío Cándido, type locality. Bottom: Anteojo. Photos by Suzanne E. McGaugh. interspecific matings between atra and emoryi at some localities. Winokur (1968) confirmed the existence of intermediates, but he concluded that hybridization was restricted and that atra was keeping its genetic integrity as a full species.

Populations of A. s. atra are dangerously low, but the taxon is not yet extinct. However, without adequate protection for the water resources of the valley, A. s. atra could be extinct soon. A population survey consisting of nine sites spanning all of the known drainages of the basin was conducted by McGaugh in 2003 and 2004. This survey indicated that A.s. atra is most abundant at Tío Cándido and Antiguos Mineros Grande, although no estimates of effective population size have been attempted from this data.

Threats to Survival. - The main threats for A. s. atra are: 1) a naturally reduced and relictual distribution; 2) an apparent introgression from emoryi; 3) current destruction and drainage of the ponds and surrounding nesting sites; and 4) inadequate conservation measures. Some of the conservation measures established for some localities must be reviewed. Because of the fencing of Tío Cándido and other localities to avoid grazing and soil erosion by horses and cattle, vegetation has grown to completely cover the margins of the ponds. This may be blocking suitable nesting sites and may have other unknown but negative consequences for the turtles. In addition, there is a certain amount of disturbance by tourism, especially swimmers.

Conservation Measures Taken. - In 2007 the original 84,000 ha Cuatrociénegas Protected Area for Flora and Fauna, initially declared in 1994 as a Natural Protected Area, was expanded to 10 times that size. The site is also currently designated as an international RAMSAR wetland, included in The Nature Conservancy's Parks in Peril program, and in 2006 it became a UNESCO Man and the Biosphere Reserve.

Apalone spinifera atra is listed as Critically Endangered by the IUCN Red List (as Apalone ater), Endangered by the US ESA, on CITES Appendix I, and a Species of Special 
Concern by the Mexican government (NORMA Oficial Mexicana NOM-059-ECOL-2001).

Conservation Measures Proposed. - First and foremost, major efforts should be expended towards achieving efficient implementation of water management for the entire valley of Cuatrociénegas. Additional surveys across the basin must be undertaken to document if other morphologically pure populations of A. s. atra still exist. In light of the few pure individuals and populations found in 1983, 1986, and 2003-04 trapping efforts, the designation of Apalone spinifera atra as a Species of Special Concern by the Mexican government should be elevated to Endangered. A complete study of the habitat requirements, including nesting habitats, is necessary as well. An urgent management program is necessary to protect and augment the habitat where atra populations still exist. Monitoring of morphologically pure atra populations and removal of A. s. emoryi morphs from critical populations of atra, should be considered for immediate implementation.

Although no detectable genetic differences from $A . s$. emoryi were found for A. s. atra at the loci examined, substantial morphological diversity across the basin does exist and studies are needed to address this genetic-morphological incongruence. Failure to detect genetic differentiation does not exclude the possibility that A. s. atra may have valuable morphological uniqueness and ecological importance.

Also, as part of basic research, it is necessary to evaluate whether the morphological diversity is a product of genetic differences or plasticity due to different environments. A more thorough genetic evaluation using a genome-wide scan such as AFLPs and common garden experiments need to be done. A thorough population genetic study across the basin is needed to determine areas of high genetic diversity and/or differentiation

Captive Husbandry. - Nothing is known about the breeding and maintenance of A. s. atra in captivity.

CurrentResearch. - Cerdá-ArduraandSoberón-Mobarak have recently proposed a long-term conservation and basic research program for the chelonian community of Cuatrociénegas. McGaugh is in the process of doing a more thorough evaluation of the genetic signature and population genetics of $A$. $s$. atra to be used in a comparative analysis with population genetics of the other two species of turtle in the basin.

Remarks. - Despite the lack of currently demonstrable genetic differentiation, A.s.atra constitutes an interesting and unique morphologic, genetic, taxonomic, and ecologic entity with high paleoecological and biogeographic value. Whether atra is conspecific with emoryi, a divergent morph, a color variant, a subspecies, or a full species, it appears to posess a unique history and genetic pool that should be preserved to allow long-term evolution. It is perilously close to extinction due to severe demographic reduction, drainage and loss of its habitats, and introgression with emoryi. Detailed studies on the ecology and natural history of both taxa are urgently needed to answer crucial questions and to aid in the design of a successful long-term conservation program for atra.

Acknowledgments. - We thank Alejandro Martinez Mena, chief of the Laboratorio de Microcine, Facultad de
Ciencias, UNAM, for his assistance in the elaboration of this account. Lauro "Guito" Veleta is thanked for logistical support in Cuatrociénegas. Sr. de la Garza granted permission to survey ponds on his ranch, including Poza del Tío Cándido. Special thanks to Robert Winokur for providing us with a copy of his Master's Thesis.

\section{LITERATURE CITED}

BARTLEy, J.A. 1971. A histological and hormonal analysis of physiological and morphological chromatophore responses in the soft-shelled turtle Trionyx sp. Journal of Zoology 163:125-144.

EngSTROM, T.N., ShafFer, H.B., AND McCord, W.P. 2004. Multiple data sets, high homoplasy, and the phylogeny of softshell turtles (Testudines: Trionychidae). Systematic Biology 53:693-710.

ERnst, C.H. And Barbour, R.W. 1992. Turtles of the World. Smithsonian Institution Press, Washington, D.C.

FrITZ,U. AND HaVAS, P. 2007. Checklist of Chelonians of the World. Vertebrate Zoology 57:149-368.

Krenz, J.G., NAYlor, G.J.P., ShafFer, H.B., AND JANZEN, F.J. 2005. Molecular phylogenetics and evolution of turtles. Molecular Phylogenetics and Evolution 37:178-191.

Le, M., RaXworthy, C.J., McCord, W.P. AND Mertz, L. 2006. A molecularphylogeny of tortoises (Testudines: Testudinidae) based on mitochondrial and nuclear genes. Molecular Phylogenetics and Evolution 40:517-531.

McGAUGH, S.E. 2008. Color variation correlated with habitat type and background coloration in Apalone spinifera in Cuatro Ciénegas, Coahuila, Mexico. Journal of Herpetology 42:347-353.

McGaUgh, S.E. AND JANZEN, F.J. 2008. The status of Apalone ater populations in Cuatro Ciénegas, Coahuila, Mexico, preliminary data. Chelonian Conservation and Biology 7(1):88-95.

McGAUGH, S.E.,ECKERMAN, C.M., AND JANZEN,F.J.2008. Molecular phylogeography of Apalone spinifera (Testudines: Trionychidae). Zoologica Scripta 37:289-304.

MORAFKA,D.J.1977.Abiogeographical analysis of the Chihuahuan desert through its herpetofauna. Biogeographica 9:1-313.

SMITH, H.M. AND SMITH, R.B. 1980. Synopsis of the Herpetofauna of Mexico. Volume VI. Guide to Mexican turtles. Bibliographic addendum III. North Bennington, Vermont: John Johnson, 1044 pp.

WeBв,R.G. 1962.NorthAmerican Recent soft-shelled turtles (family Trionychidae). Univ. Kansas Publ. Mus. Nat. Hist. 13:429-611.

WEBB, R.G. AND LEGLER, J.M. 1960. A new softshell turtle (Genus Trionyx) from Coahuila, Mexico. The University of Kansas Science Bulletin, 40:21-30.

WeisRock D.W. AND JANZEN F.J. 2000. Comparative molecular phylogeography of North American softshell turtles (Apalone): implications for regional and wide-scale historical evolutionary forces. Molecular Phylogenetics Evolution 14:152-164.

WINOKUR, R.M. 1968. The morphology and relationships of the softshelled turtles of the Cuatrociénegas Basin, Coahuila, Mexico. M.S. Thesis, Arizona State Univ., Tempe.

\section{Citation Format for this Account:}

Cerdá-Ardura, A., Soberón-Mobarak, F., McGaugh, S.E., and Vogt, R.C. 2008. Apalone spinifera atra (Webb and Legler 1960) - black spiny softshell turtle, Cuatrociénegas softshell, tortuga concha blanda, tortuga negra de Cuatrociénegas. In: Rhodin, A.G.J., Pritchard, P.C.H., van Dijk, P.P., Saumure, R.A., Buhlmann, K.A., and Iverson, J.B. (Eds.). Conservation Biology of Freshwater Turtles and Tortoises: A Compilation Project of the IUCN/SSC Tortoise and Freshwater Turtle Specialist Group. Chelonian Research Monographs No. 5, pp. 021.1-021.4, doi:10.3854/crm.5.021 atra.v1.2008, http:// www.iucn-tftsg.org/cbftt/. 